\title{
Organocatalyzed Michael Addition to Nitroalkenes via Masked Acetaldehyde
}

\author{
Giuliana Giorgianni ${ }^{1}$, Valeria Nori $\left.{ }^{1}{ }^{(}\right)$, Andrea Baschieri ${ }^{1,2}{ }^{(0}$, Laura Palombi ${ }^{1}{ }^{(1)}$ \\ and Armando Carlone ${ }^{1, *(\mathbb{D})}$ \\ 1 Department of Physical and Chemical Sciences, Università degli Studi dell'Aquila, via Vetoio, \\ 67100 L'Aquila, Italy; giuliana.giorgianni@graduate.univaq.it (G.G.); valeria.nori@graduate.univaq.it (V.N.); \\ andrea.baschieri@isof.cnr.it (A.B.); laura.palombi@univaq.it (L.P.) \\ 2 Istituto per la Sintesi Organica e la Fotoreattività, Consiglio Nazionale delle Ricerche, Via P. Gobetti 101, \\ 40129 Bologna, Italy \\ * Correspondence: armando.carlone@univaq.it; Tel.: +39-0862433036
}

Received: 9 October 2020; Accepted: 4 November 2020; Published: 9 November 2020

\begin{abstract}
A novel and safe reaction protocol for the enantioselective enamine-catalysed addition of acetaldehyde to nitroalkenes is presented; this protocol makes use of a safe acetaldehyde precursor to access important intermediates to Active Pharmaceutical Ingredients (APIs), and allows the use of fewer equivalents of acetaldehyde and lower catalyst loadings. The reaction developed proved to be suitable to be performed on gram-scale and to produce key intermediates for the synthesis of pharmacologically active compounds such as pregabalin.
\end{abstract}

Keywords: acetaldehyde; asymmetric catalysis; Michael addition; organocatalysis; pregabalin

\section{Introduction}

Nowadays, organocatalysis is a key technology platform and is routinely assessed in industry when taking a process to manufacture [1-4]. In fact, organocatalysis can bring many benefits to an industrial process; the catalysts are in general non-toxic, the reactions are robust, metals are avoided, and strictly controlled conditions are non-necessary. Organocatalysis can be employed to access very valuable $\gamma$-amino acids, such as pregabalin, and a great number of organocatalytic synthetic routes to this simple API has been disclosed [5].

Among these, the enamine-catalysed [6-9] addition of acetaldehyde to a nitroalkene holds high potential for a cost-efficient process; the raw materials are widely available at low prices and the catalyst needed can be accessed at a reasonable cost. Whereas different types of ketones and aldehydes have been activated as nucleophiles, few attempts of using acetaldehyde as nucleophile have been reported with aminocatalysis $[10,11]$. Controlling acetaldehyde's reactivity is extremely challenging; in fact, it can easily undergo self-condensation reactions. Furthermore, the product of the enamine-mediated reaction of acetaldehyde is an aldehyde carrying a methylene group, which is still considerably reactive and could potentially react with either a nucleophile or an electrophile to give collateral products. Hayashi $[12,13]$ and List [14] showed independently that, by carefully choosing the reaction conditions, an efficient aminocatalytic enantioselective addition of acetaldehyde to nitroalkenes can be accomplished (Scheme 1a,b). 


\section{Previous works}

a) Hayashi and coworkes<smiles>CC(=O)[PH2+]NC=C[18O]</smiles>

$\underset{\text { 1,4-dioxane, RT }}{\stackrel{6(10 \mathrm{~mol} \%)}{\longrightarrow}}$

$$
\text { (10 eq.) }
$$

b) List and coworkers<smiles>CC(=O)[PH2+]NC=C[18OH]</smiles>

c) Pericàs and coworkers<smiles>CC1OC(C)OC(C)O1</smiles>

8 (20 mol\%)

$\mathrm{CH}_{2} \mathrm{Cl}_{2}, \mathrm{RT}$<smiles>O=CC[C@H](Br)C[N+](=O)[O-]</smiles>

(S)-3

Yields 54\% - 77\%

ee $92 \%-99 \%$<smiles>O=CC[C@H](Br)C[N+](=O)[O-]</smiles>

(S) -3

MF, 10 eq iPrOH RT, 24-40 h

Yields 38\% - 57\% ee $94 \%-97 \%$

$\mathbf{R}^{1}$<smiles>O=CCC(Br)C[N+](=O)[O-]</smiles>

(S)-3

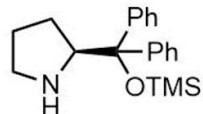

6
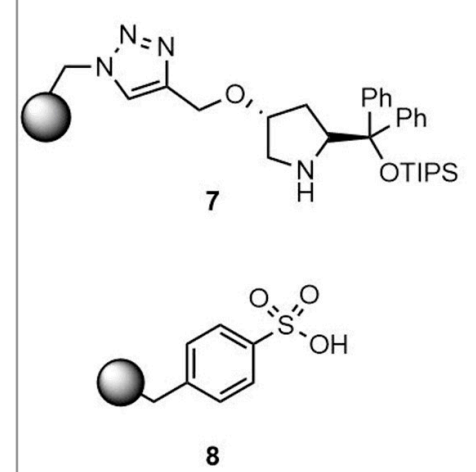

Yields 35\% - 77\% ee $87 \%-94 \%$

\section{This work}

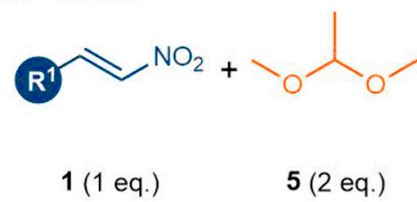

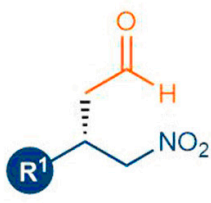

(S)-3

\section{- Lower catalyst loading}

\section{- No free acetaldehyde}

- Lower excess reagents

Scheme 1. Literature-reported examples of enantioselective Michael addition of acetaldehyde to nitroalkenes compared to our synthetic strategy.

Despite the great advancement of the reports by Hayashi and List, the approach still suffers from the use of relatively high catalyst loading (10-20 mol\%) and the use of a large excess of acetaldehyde; in fact, because of its high tendency to form oligomers, it was used in large excess and added slowly. Furthermore, by using two supported catalysts, Pericàs ingeniously employed paraldehyde to enable the same reaction and avoid the use of acetaldehyde [15] (Scheme 1c). Nevertheless, they used 10 equivalents of masked acetaldehyde (i.e., 3.3 eq. of paraldehyde) and a relatively high catalyst loading of supported organocatalysts that, despite the potential recyclability, bring a considerable cost contribution to the manufacture process.

Herein, we report the use of acetaldehyde dimethyl acetal in the aminocatalytic enantioselective addition to nitroalkenes. By employing a simple masked acetaldehyde, we could tackle the challenges that acetaldehyde brings to an industrial process, lower the catalyst loading, use fewer equivalents of acetaldehyde, and use affordable raw materials and catalyst. The desired $\gamma$-nitroaldehydes derivatives were obtained in high yields and enantioselectivities using a very simple, safe, and cost-efficient protocol.

\section{Results and Discussion}

A range of organic, inorganic, and immobilized acids were tested on the in-situ deprotection of acetaldehyde dimethyl acetal 5 (Table 1). While organic acids afforded negligible amounts of 
deprotected products (Table 1, entries 1-4), encouraging results were obtained with inorganic acids and acidic resins (Table 1, entries 5-6 and 7-8 and 10) and trifluoroacetic acid (Table 1, entry 9). The most promising acids proved to be TFA and Amberlyst-15, providing the deprotected acetaldehyde 2 in $16 \%$ and $18 \%$ conversion, respectively (Table 1, entry 9-10). Nafion NRE 212, albeit showing a similar conversion, was discarded for further screening given its higher cost and the challenges that a polymeric sheet brings in a process.

Table 1. Results of the acid-catalysed deprotection of acetaldehyde dimethyl acetal ${ }^{1}$.

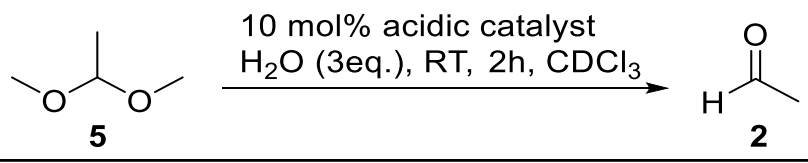

\begin{tabular}{ccc}
\hline Entry & Acid & Conv. (\%) $\mathbf{~}^{\mathbf{2}}$ \\
\hline 1 & Benzoic Acid & 0 \\
2 & AcOH & 1 \\
3 & $p-\mathrm{NO}_{2}-\mathrm{C}_{6} \mathrm{H}_{4} \mathrm{CO}_{2} \mathrm{H}$ & 0 \\
4 & $\mathrm{pTSA}$ & 0 \\
5 & $\mathrm{HCl}$ & 14 \\
6 & $\mathrm{H}_{2} \mathrm{SO}_{4}$ & 14 \\
7 & Amberlyst-36 & 12 \\
8 & Nafion NRE 212 & 15 \\
9 & TFA & 16 \\
10 & Amberlyst-15 & 18 \\
\hline
\end{tabular}

\footnotetext{
${ }^{1}$ Acetaldehyde dimethyl acetal $(0.8 \mathrm{mmol})$ and acid $(10 \mathrm{~mol} \%)$ were mixed in $\mathrm{CDCl}_{3}$ for $2 \mathrm{~h} .{ }^{2}$ Conversion of acetaldehyde dimethyl acetal 5 into acetaldehyde 2 .
}

Encouraged by these results, we further optimized the reaction conditions between nitrostyrene 1a and acetaldehyde dimethyl acetal 5 in the presence of a catalytic amount of Hayashi/Jørgensen catalyst 6, by employing Amberlyst- 15 as a catalyst to effect the deprotection (Table 2, see also Supplementary Materials); the use of TFA was discarded as no 7 is formed in the presence of TFA, $\mathbf{1 a}, \mathbf{6}$ and $\mathbf{5}$ in $\mathrm{CHCl}_{3}$. Adventitious water is not enough to afford a high conversion and the addition of water is needed (Table 2, entries 1-2). A solvent screening was carried out with 5 eq. of 5, 10 eq. of water (i.e., 2 eq. with respect to 5) over $72 \mathrm{~h}$ (Table 2, entries 2-9). Chloroform afforded the desired product 3a in $94 \%$ conversion and $93 \%$ ee (Table 2, entry 2). Solvents such as ethyl acetate, acetonitrile, and acetone showed lower conversion and enantioselectivity (Table 2, entries 3-5), while toluene, diethyl ether, and dichloromethane provided lower conversion with enantioselectivity comparable to $\mathrm{CHCl}_{3}$ (Table 2, entries 6-8). The use of dioxane provided similar conversion and ee to $\mathrm{CHCl}_{3}$ over $72 \mathrm{~h}$ (Table 2, entry 9). However, when the reaction time was shortened to $24 \mathrm{~h}, \mathrm{CHCl}_{3}$ proved to be a better solvent than dioxane both with 10 eq. (Table 2, entries 10-11) and 15 eq. of $\mathrm{H}_{2} \mathrm{O}$ (Table 2, entries 12-13).

Table 2. Optimization of conditions for the Michael addition ${ }^{1 .}$

\begin{tabular}{|c|c|c|c|c|c|c|}
\hline \multicolumn{2}{|c|}{$1 a$} & 5 & $\begin{array}{r}\text { Amberl } \\
\mathrm{s}\end{array}$ & $\begin{array}{l}(10 \mathrm{~mol} \%) \\
\text {, RT }\end{array}$ & & $\begin{array}{l}\mathrm{H} \\
\mathrm{NO}_{2}\end{array}$ \\
\hline Entry & 5 (eq) & $\mathrm{H}_{2} \mathrm{O}(\mathrm{eq})$ & Solvent & $t(\mathrm{~h})$ & Conv. $[\%]^{2}$ & ee $(\%)^{3}$ \\
\hline 1 & 5 & 0 & $\mathrm{CHCl}_{3}$ & 72 & 46 & 96 \\
\hline 2 & 5 & 10 & $\mathrm{CHCl}_{3}$ & 72 & 94 & 93 \\
\hline 3 & 5 & 10 & AcOEt & 72 & 32 & 88 \\
\hline 4 & 5 & 10 & $\mathrm{MeCN}$ & 72 & 5 & 44 \\
\hline
\end{tabular}


Table 2. Cont.

\begin{tabular}{|c|c|c|c|c|c|c|}
\hline Entry & 5 (eq) & $\mathrm{H}_{2} \mathrm{O}(\mathrm{eq})$ & Solvent & $t(\mathrm{~h})$ & Conv. $[\%]^{2}$ & ee $(\%)^{3}$ \\
\hline 5 & 5 & 10 & Acetone & 72 & 75 & 87 \\
\hline 6 & 5 & 10 & Toluene & 72 & 85 & 94 \\
\hline 7 & 5 & 10 & $\mathrm{Et}_{2} \mathrm{O}$ & 72 & 71 & 94 \\
\hline 8 & 5 & 10 & $\mathrm{CH}_{2} \mathrm{Cl}_{2}$ & 72 & 61 & 92 \\
\hline 9 & 5 & 10 & Dioxane & 72 & 93 & 94 \\
\hline 10 & 5 & 10 & Dioxane & 24 & 71 & 93 \\
\hline 11 & 5 & 10 & $\mathrm{CHCl}_{3}$ & 24 & 93 & 93 \\
\hline 12 & 5 & 15 & Dioxane & 24 & 84 & 95 \\
\hline 13 & 5 & 15 & $\mathrm{CHCl}_{3}$ & 24 & 97 & 93 \\
\hline 14 & 1.2 & 3.6 & $\mathrm{CHCl}_{3}$ & 24 & 57 & 91 \\
\hline 15 & 2 & 6 & $\mathrm{CHCl}_{3}$ & 24 & 74 & 90 \\
\hline 16 & 3 & 9 & $\mathrm{CHCl}_{3}$ & 24 & 81 & 92 \\
\hline $17^{4}$ & 3 & 9 & $\mathrm{CHCl}_{3}$ & 24 & $>99$ & 94 \\
\hline $18^{4}$ & 2 & 6 & $\mathrm{CHCl}_{3}$ & 24 & 81 & 92 \\
\hline $19^{5}$ & 2 & 6 & $\mathrm{CHCl}_{3}$ & 24 & 94 & 90 \\
\hline $20^{5,6}$ & 2 & 6 & $\mathrm{CHCl}_{3}$ & 24 & 91 & 90 \\
\hline $21^{5,7}$ & 2 & 6 & $\mathrm{CHCl}_{3}$ & 24 & 10 & 93 \\
\hline $22^{5,8}$ & 2 & 6 & $\mathrm{CHCl}_{3}$ & 24 & 0 & n.d \\
\hline $23^{9}$ & 2 & 6 & $\mathrm{CHCl}_{3}$ & 24 & 48 & 91 \\
\hline $24^{5}$ & 2 & 6 & Dioxane & 24 & 65 & 92 \\
\hline
\end{tabular}

${ }^{1}$ Reactions performed with catalyst $6(7.5 \mathrm{mg}, 0.02 \mathrm{mmol}, 0.05 \mathrm{eq})$, trans- $\beta$-nitrostyrene $1 \mathrm{a}(60 \mathrm{mg}, 0.4 \mathrm{mmol}, 1 \mathrm{eq}$.$) ,$ acetaldehyde dimethyl acetal 5, water, Amberlyst-15 (10 mol\%) and solvent $(1 \mathrm{~mL}, 0.4 \mathrm{M})$ at room temperature. ${ }^{2}$ Measured by ${ }^{1} \mathrm{H}$ NMR spectroscopy. ${ }^{3}$ Determined by chiral HPLC analysis after conversion of the aldehyde into the corresponding alcohol by reduction with $\mathrm{NaBH}_{4}$. See the Supporting Information for details. ${ }^{4} 0.5 \mathrm{~mL}$ of solvents were used, $\mathrm{M}=0.8 \mathrm{~mol} / \mathrm{L} .{ }^{5} 0.25 \mathrm{~mL}$ of solvents were used, $\mathrm{M}=1.6 \mathrm{~mol} / \mathrm{L} .{ }^{6} 7 \mathrm{mg}$ of Amberlyst- 15 were used. ${ }^{7} 28 \mathrm{mg}$ of Amberlyst-15 were used. ${ }^{8} \mathrm{~L}$-proline was used as a catalyst. ${ }^{9}$ (S)- $\alpha, \alpha$-Bis [3,5-bis(trifluoromethyl)phenyl]-2pyrrolidinemethanol trimethylsilyl ether (Jørgensen catalyst) was used as a catalyst.

Lowering the equivalents of 5 afforded a more sluggish reaction (Table 2, entries 14-16); the reactivity at 3 eq. could be restored by increasing the concentration to $0.8 \mathrm{M}$ (Table 2, entry 17), while the use of 2 eq. called for $1.6 \mathrm{M}$ conditions (Table 2, entries 18-19).

Using different amounts of Amberlyst-15 proved detrimental to the reaction (Table 2, entries 20-21), slowing it down dramatically in case of a larger amount, probably because the acetaldehyde was released too quickly, giving rise to oligomers (Table 2, entry 21).

Variation of the catalyst (Table 2, entries 22-23) and testing dioxane, one of the promising solvents, in the conditions of entry 19 (Table 2, entry 24), did not bring any improvement.

Based on the results, we chose the conditions in Table 2, entry 19, to evaluate the generality of the reaction (Table 3, see also Supplementary Materials). As expected, and in agreement with the previous reports [13-15], other nitroalkenes are less reactive than nitrostyrene. Nevertheless, nitrostyrene derivatives, having either electron-rich or electro-deficient substituents, successfully afforded the desired Michael adducts in high yields and enantioselectivity (Table 3, entries 1-4). The protocol developed proved to be successful also with alkyl-substituted nitroalkenes to give the desired products in high yields and optical purity (Table 3, entries 5-8). 
Table 3. Catalytic Michael addition of acetaldehyde dimethyl acetal 5 with various nitroalkenes ${ }^{1}$.

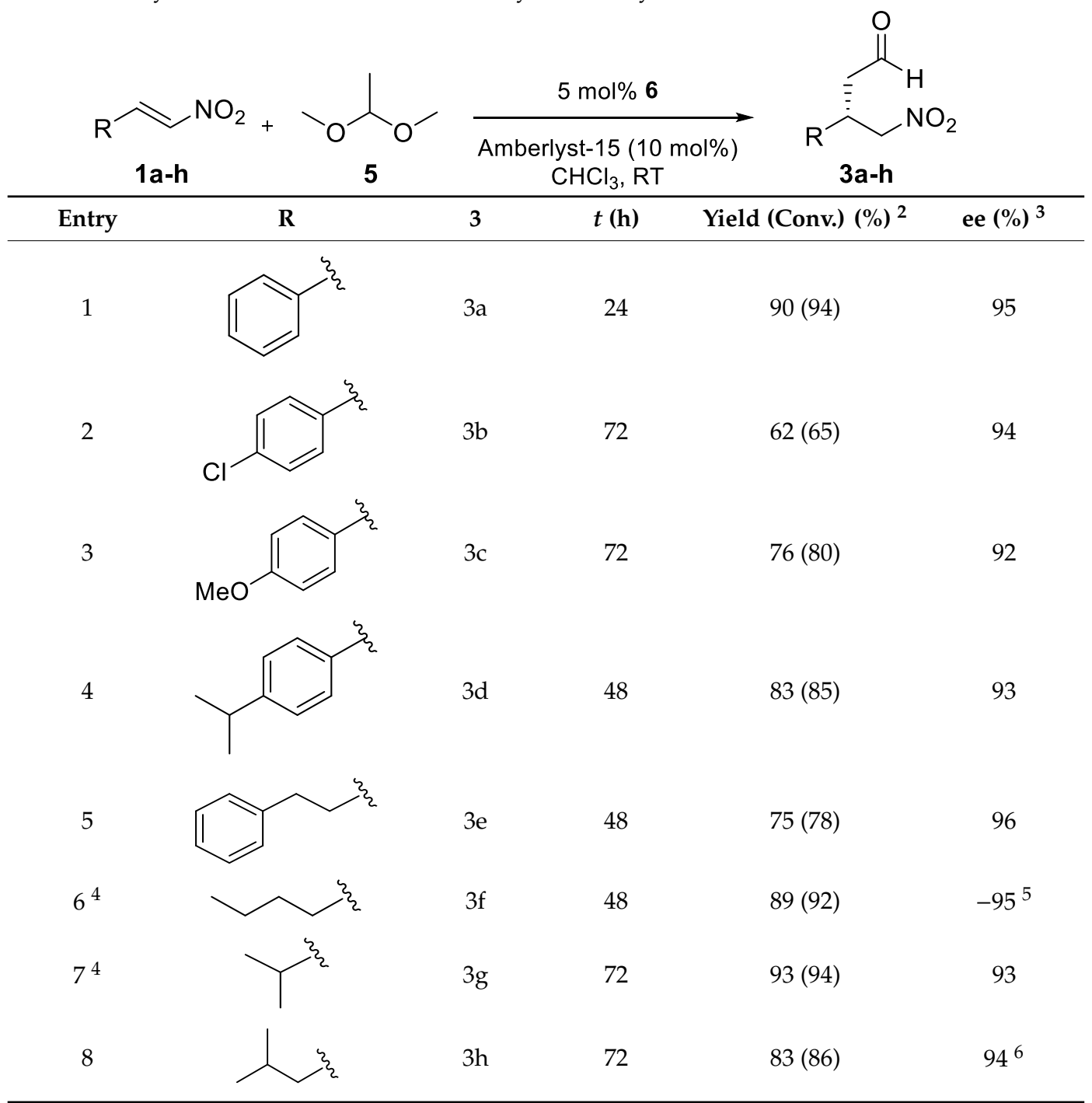

\footnotetext{
${ }^{1}$ The reaction was performed with nitroalkenes $(0.7 \mathrm{mmol}, 1 \mathrm{eq})$, acetaldehyde dimethyl acetal $\mathbf{5}(1.4 \mathrm{mmol}, 2 \mathrm{eq})$, catalyst $6(0.035 \mathrm{mmol}, 0.05 \mathrm{eq})$, Amberlyst $-15(10 \mathrm{~mol} \%)$, water $(4.2 \mathrm{mmol}, 6 \mathrm{eq})$ in $\mathrm{CHCl}_{3}(0.44 \mathrm{~mL}, 1.6 \mathrm{M})$ at room temperature. ${ }^{2}$ Yield of isolated product. ${ }^{3}$ Optical purity was determined by chiral HPLC/GC analysis after conversion of the aldehyde into the corresponding alcohol by reduction with $\mathrm{NaBH}_{4} .{ }^{4}$ Amberlyst- $15(5 \mathrm{~mol} \%)$ was used. ${ }^{5}(R)-6$ was used as a catalyst. ${ }^{6}$ Optical purity was determined after conversion of the corresponding alcohol into the tosylate derivative.
}

As anticipated at the outset, the catalytic Michael reaction affords nitroaldehydes that are versatile and key intermediates to access important APIs, such as pregabalin [16], a widely used anti-epileptic drug. The developed protocol was tested on $>1 \mathrm{~g}$ scale of the starting nitroalkene $1 \mathrm{~h}$ to provide a more reliable expectation of how it should behave on bigger scales (Scheme 2, see also Supplementary Materials). The reaction was stopped after $72 \mathrm{~h}$; the yield proved to be in line with the smaller scale, while the enantioselectivity was higher than on a smaller scale and nearly complete $(>99 \%)$, pointing to the fact that the protocol is very promising for further development. 


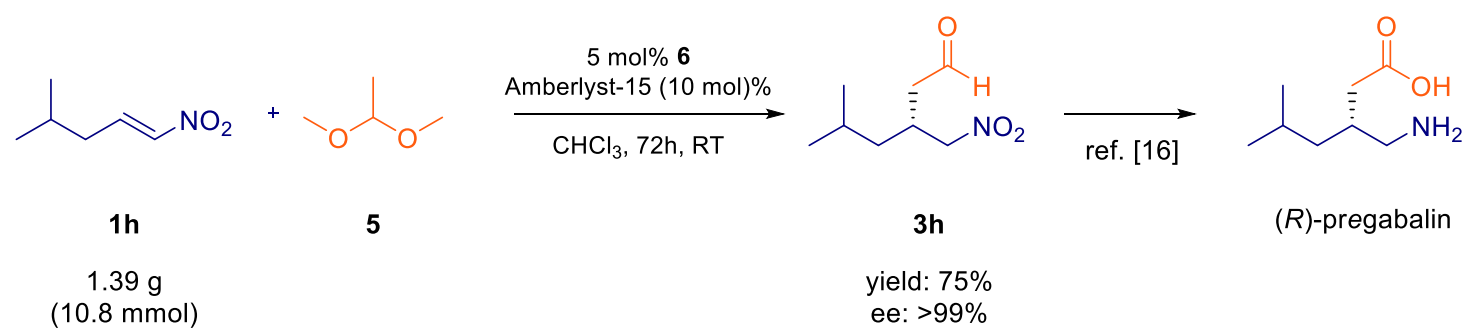

Scheme 2. Application of the developed protocol on $>1 \mathrm{~g}$ scale to afford synthetically useful intermediate $3 \mathbf{h}$.

\section{Conclusions}

In conclusion, we have developed an industrially interesting protocol for the Michael addition of acetaldehyde to nitroalkenes, affording the corresponding products in high yields and ee. A current limitation of the presented reaction is the use of a class 2 solvent; however, we believe that further R\&D can tackle this issue. The presented reaction makes use of a masked acetaldehyde to avoid the use of a highly toxic and reactive intermediate. Furthermore, the use of an acidic resin and low amounts of an affordable organocatalyst make the overall protocol appealing for more in-depth studies to assess its application in manufacture.

\section{Materials and Methods}

Typical procedure: acetaldehyde dimethyl acetal $5(148 \mu \mathrm{L}, 1.4 \mathrm{mmol})$ was added to a mixture of (S)-diphenyltrimethylsiloxymethyl pyrrolidine $6(11.4 \mathrm{mg}, 0.035 \mathrm{mmol})$, trans- $\beta$-nitrostyrene 1a (105 mg, $0.7 \mathrm{mmol})$, Amberlyst-15 $\left(10 \mathrm{~mol} \%, \mathrm{H}^{+}\right.$exchange capacity $\left.(4.7 \mathrm{meq} / \mathrm{g})\right)$, water $(76 \mu \mathrm{L}$, $4.2 \mathrm{mmol})$ and $\mathrm{CHCl}_{3}(0.44 \mathrm{~mL})$. The reaction mixture was stirred at room temperature for $24 \mathrm{~h}$ and then quenched with $1 \mathrm{~mL} 1 \mathrm{M} \mathrm{HCl}$. Then, the aqueous mixture was extracted with ethyl acetate $(3 \times 3 \mathrm{~mL})$. The combined organic layers were dried over anhydrous $\mathrm{MgSO}_{4}$, filtered and concentrated in vacuo. Purification by flash chromatography on silica gel (petroleum ether/ethyl acetate $=90: 10$ ) gave (S)-4-nitro-3-phenylbutanal 3a (122 mg, $0.63 \mathrm{mmol})$ in 90\% yield and 95\% ee. The enantiomeric excess was determined by chiral HPLC analysis after conversion of the aldehyde into the corresponding alcohol by reduction with $\mathrm{NaBH}_{4}$.

Supplementary Materials: General procedures, preparation of starting materials, characterization of compounds, ${ }^{1} \mathbf{H}$ and ${ }^{13} \mathbf{C}$ NMRs, and HPLC traces are available online at http://www.mdpi.com/2073-4344/10/11/1296/s1.

Author Contributions: Methodology, investigation, analysis, data curation, writing-original draft preparation: G.G. and V.N. Writing-review and editing, supervision and funding acquisition: L.P., A.B. and A.C. Conceptualisation and project administration: A.C. All authors have read and agreed to the published version of the manuscript.

Funding: G.G. is grateful to PON-DOT13OV2OC for an industrial PhD fellowship. A.B. acknowledges PON-AIM1842894, CUP E18D19000560001 for support. A.C. and A.B. acknowledge Royal Society of ChemistryResearchFund (RF19-5583 and R19-3106) for support.

Acknowledgments: A.C. is extremely grateful to Fred Cederbaum and Nikola Kokosar, Syngenta Crop Protection Research Center-Stein (CH), Angelini Fine Chemicals Process Development-Aprilia (I), Reddy's-Cambridge (UK), and Discovery Department, Dompè farmaceutici SpA-L'Aquila (I), for their generous support. Francesco Fini (Università di Modena e Reggio Emilia) is acknowledged for HRMS analysis. Giorgio Bencivenni (Alma Mater Studiorum-Università di Bologna) is acknowledged for help with chiral HPLC analysis of 3e.

Conflicts of Interest: The authors declare no conflict of interest. The funders had no role in the design of the study; in the collection, analyses, or interpretation of data; in the writing of the manuscript, or in the decision to publish the results. 


\section{References}

1. Carlone, A.; Bernardi, L. Enantioselective organocatalytic approaches to active pharmaceutical—Selected industrial examples. Phys. Sci. Rev. 2019, 4, 20180097. [CrossRef]

2. Blaser, H.U.; Federsel, H.J. Asymmetric Catalysis on Industrial Scale: Challenges, Approaches and Solutions, 2nd ed.; WILEY-VCH Verlag GmbH \& Co. KGaA: Weinheim, Germany, 2010; ISBN 9783527324897.

3. Wallace, D.; Challenger, S.; Ding, Z.D.; Osminski, W.E.G.; Ren, H.; Wulff, W.D.; Desai, A.A.; Munmun, M.; Scott, J.P.; Alam, M.; et al. Special feature section: Asymmetric synthesis on large scale. Org. Process. Res. Dev. 2011, 15, 1088-1211. Available online: https://pubs.acs.org/toc/oprdfk/15/5 (accessed on 9 November 2020). [CrossRef]

4. Dunn, P.J.; Hii, K.K.; Krische, M.J.; Williams, M.T. Sustainable Catalysis: Challenges and Practices for the Pharmaceutical and Fine Chemical Industries; John Wiley \& Sons, Inc.: Hoboken, NJ, USA, 2013; ISBN 9781118155424.

5. Adamo, M.F.A.; Kelly, B.G.; Moccia, M. Recent advances in the preparation of active pharmaceutical ingredient (S)-Pregabalin. Chim. Oggi Chem. Today 2016, 34, 54-57.

6. Dalko, P.I. Comprehensive Enantioselective Organocatalysis: Catalysts, Reactions, and Applications; Wiley-VCH Verlag GmbH \& Co. KGaA: Weinheim, Germany, 2013; Volume 1-3, ISBN 9783527658862.

7. List, B. Asymmetric Organocatalysis in Topics in Current Chemistry; Springer: Berlin, Germany; New York, NY, USA, 2009; ISBN 978-3-642-02815-1.

8. Torres, R.R. Stereoselective Organocatalysis: Bond Formation Methodologies and Activation Modes; Wiley: Hoboken, NJ, USA, 2013; ISBN 978-1-118-60470-0.

9. Melchiorre, P.; Marigo, M.; Carlone, A.; Bartoli, G. Asymmetric aminocatalysis-Gold rush in organic chemistry. Angew. Chem. Int. Ed. 2008, 47, 6138-6171. [CrossRef] [PubMed]

10. Córdova, A.; Notz, W.; Barbas, C.F. Proline-catalyzed one-step asymmetric synthesis of 5-hydroxy-(2E)hexenal from acetaldehyde. J. Org. Chem. 2002, 67, 301-303. [CrossRef] [PubMed]

11. Bøgevig, A.; Kumaragurubaran, N.; Jørgensen, K.A. Direct catalytic asymmetric aldol reactions of aldehydes. Chem. Commun. 2002, 2, 620-621. [CrossRef] [PubMed]

12. Hayashi, Y.; Itoh, T.; Aratake, S.; Ishikawa, H. A diarylprolinol in an asymmetric, catalytic, and direct crossed-aldol reaction of acetaldehyde. Angew. Chem. Int. Ed. 2008, 47, 2082-2084. [CrossRef]

13. Hayashi, Y.; Itoh, T.; Ohkubo, M.; Ishikawa, H. Asymmetric Michael reaction of acetaldehyde catalyzed by diphenylprolinol silyl ether. Angew. Chem. Int. Ed. 2008, 47, 4722-4724. [CrossRef] [PubMed]

14. García-García, P.; Ladépêche, A.; Halder, R.; List, B. Catalytic asymmetric michael reactions of acetaldehyde. Angew. Chem. Int. Ed. 2008, 47, 4719-4721. [CrossRef] [PubMed]

15. Fan, X.; Rodríguez-Escrich, C.; Sayalero, S.; Pericàs, M.A. Paraldehyde as an acetaldehyde precursor in asymmetric michael reactions promoted by site-isolated incompatible catalysts. Chem. Eur. J. 2013, 19, 10814-10817. [CrossRef] [PubMed]

16. Gotoh, H.; Ishikawa, H.; Hayashi, Y. Diphenylprolinol silyl ether as catalyst of an asymmetric, catalytic, and direct michael reaction of nitroalkanes with $\alpha, \beta$-unsaturated aldehydes. Org. Lett. 2007, 9, 5307-5309. [CrossRef] [PubMed]

Publisher's Note: MDPI stays neutral with regard to jurisdictional claims in published maps and institutional affiliations.

(C) 2020 by the authors. Licensee MDPI, Basel, Switzerland. This article is an open access article distributed under the terms and conditions of the Creative Commons Attribution (CC BY) license (http://creativecommons.org/licenses/by/4.0/). 